\title{
The role of self-efficacy, recovery self-efficacy, and preparatory planning in predicting short-term smoking relapse
}

Citation for published version (APA):

Elfeddali, I., Bolman, C., Candel, M. J. J. M., Wiers, R. W., \& De Vries, H. (2012). The role of self-efficacy, recovery self-efficacy, and preparatory planning in predicting short-term smoking relapse. British Journal of Health Psychology, 17, 185-201. https://doi.org/10.1111/j.2044-8287.2011.02032.x

Document status and date:

Published: 01/02/2012

DOI:

10.1111/j.2044-8287.2011.02032.x

Document Version:

Publisher's PDF, also known as Version of record

Document license:

Taverne

Please check the document version of this publication:

- A submitted manuscript is the version of the article upon submission and before peer-review. There can be important differences between the submitted version and the official published version of record.

People interested in the research are advised to contact the author for the final version of the publication, or visit the DOI to the publisher's website.

- The final author version and the galley proof are versions of the publication after peer review.

- The final published version features the final layout of the paper including the volume, issue and page numbers.

Link to publication

\footnotetext{
General rights rights.

- You may freely distribute the URL identifying the publication in the public portal. please follow below link for the End User Agreement:

www.umlib.nl/taverne-license

Take down policy

If you believe that this document breaches copyright please contact us at:

repository@maastrichtuniversity.nl

providing details and we will investigate your claim.
}

Copyright and moral rights for the publications made accessible in the public portal are retained by the authors and/or other copyright owners and it is a condition of accessing publications that users recognise and abide by the legal requirements associated with these

- Users may download and print one copy of any publication from the public portal for the purpose of private study or research.

- You may not further distribute the material or use it for any profit-making activity or commercial gain

If the publication is distributed under the terms of Article $25 \mathrm{fa}$ of the Dutch Copyright Act, indicated by the "Taverne" license above, 


\title{
The role of self-efficacy, recovery self-efficacy, and preparatory planning in predicting short-term smoking relapse
}

\author{
I. Elfeddali ${ }^{1,2 *}$, C. Bolman ${ }^{3}$, M. J. J. M Candel ${ }^{1,4}$, R. W. Wiers ${ }^{5}$ \\ and $H$. De Vries ${ }^{1,2}$
}

'Care and Public Health Research Institute (Caphri), Maastricht University, Maastricht, The Netherlands

${ }^{2}$ Department of Health Promotion, Maastricht University, Maastricht, The Netherlands

${ }^{3}$ Department of Psychology, Open University of the Netherlands, Heerlen, The Netherlands

${ }^{4}$ Department of Methodology and Statistics, Maastricht University, Maastricht, The Netherlands

${ }^{5}$ Department of Psychology, University of Amsterdam, Amsterdam, The Netherlands

Objectives. This study aims to identify the role of self-efficacy, recovery self-efficacy, and preparatory planning with regard to short-term smoking relapse. We also assessed whether the importance of these variables differed for smokers quitting individually and without help (self-quitters) and smokers quitting with the help of a smoking cessation course (group quitters).

Design. A longitudinal quasi-experimental study with follow-ups at I and 3 months after the quit attempt was conducted in order to assess the role of baseline self-efficacy, recovery self-efficacy, and preparatory planning on short-term relapse.

Methods. The recruitment included adult daily smokers $(N=121)$, quitting in a smoking cessation course $(N=57)$ and self-quitters $(N=64)$. Respondents received internet-based questionnaires 2 weeks before quitting (baseline) and $\mathrm{I}$ and 3 months after the quit attempt. Predictors of relapse were analysed using logistic regression analyses.

Results. Relapse at I and 3 months after the quit attempt was predicted by low levels of baseline self-efficacy. Simple slope analyses revealed that less preparatory planning significantly predicted relapse at I month after the quit attempt among group quitters, but not among self-quitters. Recovery self-efficacy was only predictive of relapse after

\footnotetext{
*Correspondence should be addressed to Iman Elfeddali, Department of Health Promotion, Maastricht University, PO Box 6I6, 6200 MD, Maastricht, the Netherlands (e-mail: iman.elfeddali@maastrichtuniversity.nl).
} 
I month when self-efficacy was excluded from the analyses. Moreover, among group quitters, the results indicated a borderline significant curved relation between recovery self-efficacy and relapse after I month.

Conclusions. Our results suggest that more research is needed on the role of preparatory planning and recovery self-efficacy. Moreover, we recommend incorporating self-efficacy increasing techniques in relapse-prevention interventions.

Worldwide, smoking is the largest preventable behavioural cause of mortality and disability, and a risk factor for six of the eight leading causes of death (Danaei et al., 2010; WHO, 2001). In 2010, approximately $28 \%$ of the Dutch population smoked (STIVORO, 2010), while smoking prevalence in the United States is about 20\% (CDC, 2002). Although $70 \%$ of the smokers worldwide want to quit smoking and $45 \%$ try to quit each year, most quit attempts result in a relapse (CDC, 2002). A review regarding relapse curves showed that most relapse occurs in the first days or weeks after the quit attempt, with relapse rates of $49-76 \%$ in the first week after the quit attempt, and $80-90 \%$ after 3 months (Hughes, Keely, \& Naud, 2004). Multiple quit attempts are often needed in order to quit successfully (American Cancer Society, 2010; CTUMS, 2001). Resuming smoking after a quit attempt is referred to as smoking relapse. The Russell Standard's definition of relapse is smoking at least five cigarettes after the quit attempt (West, Hajek, Stead, \& Stapleton, 2005). To increase the likelihood of successful quitting, insight into the factors that predict smoking relapse among smokers with a high intention to quit smoking is necessary.

In general, intention is postulated as the most proximal predictor of behaviour, such as smoking cessation, according to classic social cognitive theories such as the Theory of Reasoned Action (Ajzen \& Fishbein, 1980; Fishbein \& Ajzen, 2010), Theory of Planned Behaviour (Ajzen, 1988, 1991), Social Cognitive Theory (Bandura, 1986), and Precaution Motivation Model (Rogers, 1983). Meta-analyses of the predictive value of intention as proximal antecedent of behaviour have pointed out, however, that intention only explains $28 \%$ of the variance in behaviour, so a considerable amount remains unexplained (Sheeran, 2002; Webb \& Sheeran, 2006). Recent studies have therefore focused on factors that can predict behaviour beyond intention, including the I-Change Model (e.g., De Vries et al., 2003; De Vries, Kremers, Smeets, Brug, \& Eijmael, 2008; Hoving, Mudde, \& de Vries, 2006) that emphasizes the role of self-efficacy and preparatory planning as post-intentional predictors of behavioural change (see Figure 1).

Self-efficacy is a widely studied concept defined as the confidence a person has to perform certain behaviour successfully in high-risk situations (Bandura, 1997). In accordance with the assumptions of classical social cognitive theories, the I-Change Model accentuates the role of self-efficacy as a direct predictor of behaviour. Selfefficacy is incorporated as the immediate antecedent in the Relapse Prevention Model by Marlatt (Allen, Bade, Hatsukami, \& Center, 2008; Marlatt \& Donovan, 2005; Marlatt \& Gordon, 1985). Empirical testing of the role of self-efficacy on smoking relapse showed that low self-efficacy predicts relapse (Dijkstra \& Borland, 2003; Dijkstra \& De Vries, 2000; Gwaltney, Metrik, Kahler, \& Shiffman, 2009; Mudde, Kok, \& Strecher, 1995). An important component of self-efficacy for smoking cessation is recovery self-efficacy (Bandura, 1986; Dijkstra \& De Vries, 2000; Marlatt, Baer, \& Quigley, 1995). With regard to smoking, this is aimed at the belief that one will be able to resume the quit attempt after a lapse (Dijkstra \& De Vries, 2000). The social cognitive theory assumes that recovery self-efficacy should be high enough to trigger a smoker to resume a quit attempt, but not too high as that could lead to experimenting with lapses (Bandura, 1986). A study testing 


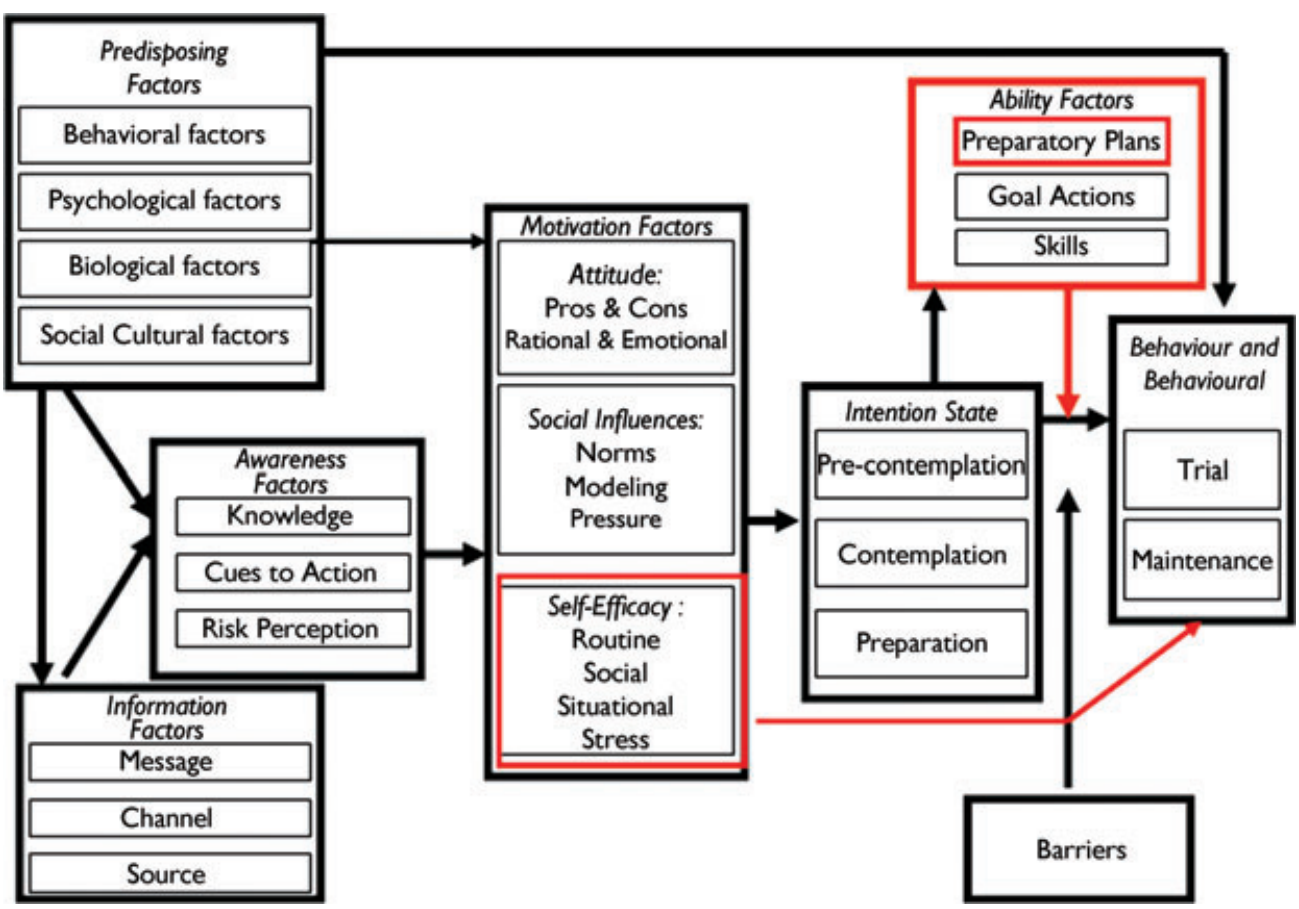

Figure I. The I-Change Model I.3, de Vries et al. Note. The red path represents the post-motivational factors of preparatory planning and self-efficacy.

the role of recovery self-efficacy in smoking cessation confirmed this assumption and pointed out that quitters with moderate levels of recovery self-efficacy were significantly more often abstinent one year later, compared with those with low and high levels of recovery self-efficacy (Haaga \& Stewart, 1992).

Preparatory plans (also referred to as 'goal intentions' in the literature; De Vries et al., 2003; Gollwitzer \& Moskowitz, 1996) are defined as sub-goals identified in the process of behavioural change, in which thoughts, feelings, and actions are directed by systematic effort towards the attainment of goals (De Vries et al., 2003; Zimmermann, 2000). According to the I-Change Model, preparatory plans are one of the most important factors that translate intention into behaviour. Appropriate preparatory plans have been shown to foster successful behavioural change and maintenance of behaviour in non-smoking-related studies (Abraham et al., 1999; Jones, Abraham, Harris, Schulz, \& Chrispin, 2001; Luszczynska \& Schwarzer, 2003; Rise, Thompson, \& Verplanken, 2003) as well as smoking-related studies (Hilberink, Jacobs, Schlosser, Grol, \& De Vries, 2006; Hoving et al., 2006). The specific role of preparatory plans in smoking relapse was recently identified in a Dutch study (Hoving et al., 2006). Further, Sun and colleagues compared the cognitive, affective, and effective experimental processes of change used by successful quitters, relapsers, and non-quitters, and speculated that those who relapse may lack adequate preparation for effective cessation (Sun, Prochaska, Velicer, \& Laforge, 2007). The previous studies assessed individual factors such as self-efficacy in relation to relapse. Yet, little data are presented that assesses how the combination of self-efficacy, recovery self-efficacy, and preparatory plans relates to relapse. 
Furthermore, studies have shown that quitting with help increases the likelihood of success, although effective smoking relapse prevention programmes remain scarce (CBO, 2009; Fiore, et al. 2008; Hajek, Stead, West, \& Jarvis, 2005; Lancaster \& Stead, 2005; Willemsen, Wagema, \& Schayck van, 2003; Zhu et al., 1996). In addition, only a small percentage of smokers seek help to quit smoking. About $70 \%$ of smokers still try to quit without help, and this indicates that smokers use different modalities to quit smoking (Cokkinides, Ward, Jemal, \& Thun, 2005; Nagelhout, de Korte, Zeegers, van der Meer, \& Willemsen, 2010; Zhu, Melcer, Sun, Rosbrook, \& Pierce, 2000). Several studies have already indicated factors that determine participation in a smoking cessation group programme (Hublet, Maes, \& Csincsak, 2002; Pohl, Matinelli, \& Antonakos, 1998). These studies indicated that low levels of self-efficacy combined with high intentions to quit smoking determine participation in a group. This might suggest that group quitters and self-quitters differ in their cognitions. Group processes are characterized by social influences such as social modelling and social support (Bandura, 1986). According to social learning theories, these social influences play a role in changing cognitions such as self-efficacy (Bandura, 1986). Moreover, most smoking cessation courses explicitly use strategies (e.g., social modelling) to increase self-efficacy and motivate respondents to engage in planning in order to reach successful quitting. This suggests that smokers participating in cessation courses are exposed to intensive and interactive strategies, which play a role in changing their baseline cognitions. Consequently, it can be expected that the effect of concepts such as self-efficacy and planning, measured at baseline, can be moderated by group participation. Consequently, baseline levels of self-efficacy, for example, may then be less predictive of relapse for group quitters. They will be subject to positive changes due to social influences associated with group participation as well as specific strategies used to increase self-efficacy and planning. The same process applies to the role of planning. Insight into baseline differences between self-quitters and group quitters as well as whether the strength of these predictors differs for smokers using different quitting modalities, is essential to better understand potential differences in pathways of change between smokers who quit individually or in a group.

The first aim of this study is, therefore, to assess baseline differences between group and self-quitters. Based on previous studies (Hublet et al., 2002; Pohl et al., 1998), we expected group quitters to have lower levels of self-efficacy and to engage in more preparatory planning than self-quitters (hypothesis 1). Moreover, we aim to assess differences in relapse rates between self-quitters and group quitters. The second and main objective of the present study is to assess the role of self-efficacy, recovery self-efficacy, and preparatory planning in relapse among smokers who are motivated to quit smoking within 2 weeks. The I-Change Model is used as the research model, with a focus on post-motivational factors. We expect low levels of selfefficacy, low levels of recovery self-efficacy, and less preparatory planning to predict smoking relapse (hypothesis 2). Third, insight into the differences in predictors of relapse per quitting modality will be valuable in optimising smoking counselling for smokers wishing to quit on their own without guidance (self quitters) or through a smoking cessation course (group quitters). Therefore, the last goal of the study aims to assess whether the role of baseline self-efficacy, recovery self-efficacy, and preparatory plans differs per quitting modality. As group quitters are motivated to plan and prepare their quit attempt and are provided with strategies to increase (recovery) self-efficacy, we expect low levels of self-efficacy and recovery self-efficacy as well as less preparatory planning to predict relapse in self-quitters but not in group quitters (hypothesis 3). 
Group quitters

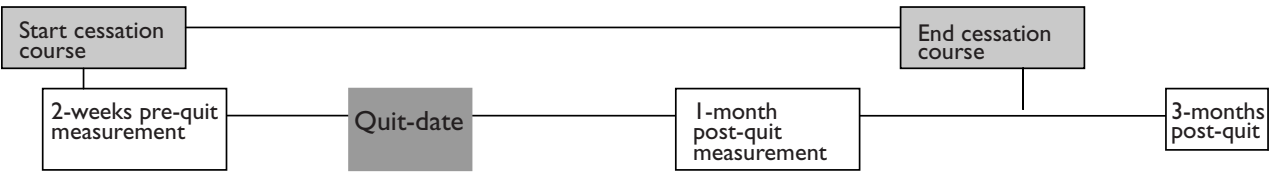

Self-quitters

\begin{tabular}{|l|l|l|l|}
\hline $\begin{array}{l}\text { 2-weeks pre-quit } \\
\text { measurement }\end{array}$ & Quit-date & $\begin{array}{l}\text { I-month } \\
\text { post-quit } \\
\text { measurement }\end{array}$ & 3-months \\
\cline { 2 - 4 } post-quit
\end{tabular}

Figure 2. Design of the study.

\section{Methods}

Ethical approval for this study was obtained from the Medical Ethics Committee.

\section{Study design, respondents, and recruitment}

Respondents $(N=121)$ were daily smokers between the ages of 18 and 65 who were willing to quit smoking within 2 weeks. The design of the study was quasiexperimental. Respondents were recruited from two groups: (1) Self-quitters and (2) group quitters. The self-quitters $(n=64)$ stopped smoking on their own without help from a structured smoking cessation course. They were recruited through advertisements in local newspapers. The group quitters $(n=57)$ were participants of a national smoking cessation course offered by The Dutch Foundation for a Smoke-Free Future (STIVORO) (see next section for more information on the course). The group quitters were recruited through flyers sent to course trainers asking them to participate in the study upon starting the course. Both advertisements and flyers contained information about the purpose of the study, the relevant website, and indicated how respondents could register for participation. All respondents needed to give consent for participation. They were told that participation involved filling in the baseline questionnaire 2 weeks before the quit attempt and 2 follow-up questionnaires at 1 and 3 months afterwards. The detailed design of the study is shown in Figure 2.

\section{Smoking cessation course}

One of the smoking cessation courses in the Netherlands, is called Pak je Kans (Grab your Chance), and is organized by STIVORO. The course consists of nine meetings each lasting an hour and a half. The meetings took place over 3 months and aim to help smokers quit successfully by keeping them motivated to quit, helping them to prepare their quit attempt, and deal with difficult situations and lapses. The meetings address four phases of the quitting process: (1) Preparation; (2) Action; (3) Maintenance; and (4) Emergency Plans (aimed at dealing with possible lapses). The first session focuses on 
nicotine dependence and stages of change. In the second session, participants are asked to identify their perceived pros and cons of smoking and a balance is made. In this session, the participants also need to make the decision to quit smoking and to make a quit attempt during the next week with a deadline of the third session. The third session focuses entirely on the quit attempt and what it will be like to be a non-smoker. In this session, the participants are asked to identify difficult situations and strategies to help them remain smoke free in order to increase self-efficacy. The participant is supposed to quit at the end of this session. The fourth session focuses on the effects of non-smoking on the body and health and on dealing with withdrawal symptoms and difficult situations. Sessions five to eight focus on dealing with difficult situations, lapses and relapse prevention, and thus maintaining/increasing (recovery) self-efficacy to remain smoke free. The last session includes an evaluation session. In this session, the course targets recovery self-efficacy and the participants again make an emergency plan to deal with possible lapses in the future. The groups consist of an average of 10-12 participants. The meetings are led by coaches who are trained and professionally licenced to give smoking cessation courses by STIVORO. Approximately $85 \%$ of the coaches had a higher vocational educational background in nursing; a few had a Masters degree in psychology. The course is packaged as a workshop with information sessions (e.g., regarding nicotine uptake in the brains), intensive assignments (e.g., to deal with possible smoking-related high-risk situations), and possibilities to learn from and exchange experiences with fellow group participants.

\section{Pre-quit measurement}

Demographic Variables were assessed with questions on age, gender, and social economical status (SES). We used income (low compared to the middle [average] income in the Netherlands was coded as low SES and average and high income were coded as high SES) as a SES measure.

Self-Efficacy (SE) was measured with 14 items. Respondents were asked whether they thought they would be able to refrain from smoking in various difficult situations (at a party, with friends). The scale had already been successfully used in several other studies (Dijkstra \& de Vries, 2000; Dijkstra, de Vries, \& Bakker, 1996; Te Poel, Bolman, Reubsaet, \& de Vries, 2009). Answers were given on a 7-point scale from totally disagree (1) to totally agree (7), with a high score representing high self-efficacy. The mean of the 14 items was used as the scale score in the analysis $(\alpha=.97)$.

Recovery Self-Efficacy (RSE) was measured with the five-item scale composed by Dijkstra and de Vries ( 2000) (e.g., 'Do you think you could quit again if you smoked for 1 day after not smoking for a month?'). Respondents were asked to rate the extent to which they felt confident they could quit smoking again after a lapse. Answers were given on a 7-point scale from totally disagree (1) to totally agree (7), with a high score representing a high level of recovery self-efficacy. The mean of the five items was used as the scale score in the analyses $(\alpha=.92)$.

Preparatory Plans were assessed using 18 items asking respondents to indicate whether they planned to perform preparatory behaviour (e.g., 'I plan to remove all smoking materials from my home'). The scale composed for this study was based on previous preparatory scales (Hilberink et al., 2006; Hoving et al., 2006; Te Poel et al., 2009). Answers were given on a 5-point scale from totally disagree (1) to totally agree (5), with a high score indicating a strong intention to perform preparatory 
behaviour. The mean score of the 18 items was used as the scale score in the analysis $(\alpha=.88)$.

\section{Post-quit measurements after I and 3 months}

Continued abstinence was measured by asking whether the respondent had smoked more or fewer than five cigarettes after the initial quit attempt (see Figure 2 for information about the quit attempt). Smoking more than five cigarettes was coded as 'relapse' (1) and smoking fewer than five was coded as 'abstinent' (0). This definition of relapse conforms to the Russell Standard (West et al., 2005).

\section{Analysis}

Differences at the pre-quit measurement between self-quitters and group quitters were assessed using chi-square tests for categorical variables and $t$-tests for continuous variables. A correlation matrix for self-efficacy, recovery self-efficacy, preparatory plans, and the outcome variables was made by calculating correlations between these variables. The role of self-efficacy, recovery self-efficacy, and preparatory planning in predicting smoking relapse was analysed using logistic regression taking these factors in one block. We corrected for quitting modality (self-quitters or group quitters), gender, age, and SES. In order to assess the differential effects of preparatory plans, self-efficacy, and recovery self-efficacy, we added the interaction terms (group $\times$ self-efficacy, group $\times$ recovery self-efficacy, group $\times$ preparatory plans) in the second block and used the BACKWARD method to assess their influence. We used this complete model (including the significant interaction terms) as the end model in this study. In the case of a differential effect of a variable, we conducted simple slope analysis using the method proposed by Aiken and West ( 1991). We checked for multicollinearity and centred the continuous variables used in the interaction terms. The analysis was a complete case analysis (using list-wise deletion with regard to the independent variables) as we omitted respondents with missing scores on the dependent variables. The dependent variables were relapse at 1 and 3 months. Finally, chi-square tests were used to assess the difference in relapse rates at 1 and 3 months after the quit attempt between the self-quitters and group quitters.

\section{Results}

\section{Sample characteristics}

A total of 121 (of whom 114 filled out the follow-ups, see 'missing data' below) respondents made a successful quit attempt and were included in this study. Table 1 shows the baseline characteristics. The mean age of the respondents was 37 years and $51.2 \%$ were female. On average, the respondents smoked 15 cigarettes a day and $81 \%$ had made previous attempts to quit. Analysis showed no significant differences at baseline in demographical variables and variables related to smoking behaviour between the self-quitters and group quitters. In our first hypothesis, we expected that group quitters would have lower levels of self-efficacy and would engage in more preparatory planning than self-quitters at baseline. The results pointed out significant differences in the level of self-efficacy between group quitters and self-quitters. The group quitters had higher levels of self-efficacy at baseline. No differences were found regarding recovery self-efficacy and planning. 
Table I. Means and differences between self-quitters and group quitters in demographic variables, smoking-related variables, and post-motivational factors

\begin{tabular}{|c|c|c|c|c|}
\hline Variables & $\begin{array}{l}\text { Overall } \\
(N=121)\end{array}$ & $\begin{array}{l}\text { Self-quitters } \\
\quad(N=64)\end{array}$ & $\begin{array}{l}\text { Group quitters } \\
\qquad(N=57)\end{array}$ & $t$-test $/ \chi^{2}$ \\
\hline Gender (\% female) & 51.2 & 54.7 & 47.4 & 0.646 \\
\hline Age (mean [SD]) & $37.13(6.34)$ & $36.22(6.13)$ & $38.16(6.46)$ & -1.693 \\
\hline SES (\% high ses) & 21.8 & 16.1 & 28.1 & 2.480 \\
\hline $\begin{array}{l}\text { Number of cigarettes } \\
\text { smoked per day (mean } \\
{[S D] \text { ) }}\end{array}$ & $15.06(6.72)$ & I5.24 (7.15) & I4.86 (6.28) & 0.307 \\
\hline $\begin{array}{l}\text { Number of years of } \\
\text { smoking (mean [SD]) }\end{array}$ & $21.46(6.72)$ & $21.89(6.94)$ & $20.98(6.46)$ & 0.742 \\
\hline $\begin{array}{l}\text { Previous quit attempts } \\
\text { (\% yes) }\end{array}$ & 81.0 & 82.8 & 78.9 & 1.435 \\
\hline Self-efficacy & $3.91(1.96)$ & $3.44(1.70)$ & $4.43(2.11)$ & $-2.808^{*}$ \\
\hline Recovery self-efficacy & $3.89(2.05)$ & $3.86(1.99)$ & $3.92(2.13)$ & -0.142 \\
\hline Preparatory planning & $2.42(.80)$ & $2.33(.70)$ & $2.53(.89)$ & -1.364 \\
\hline
\end{tabular}

Note. ${ }^{*} p<.05$.

\section{Missing data}

Seven respondents were ineligible for the follow-up and were not included in the analyses. One respondent was omitted from the analyses as they missed scores on one of the independent variables.

\section{Relapse rates}

Table 2 presents the relapse rates for both self-quitters and group quitters and the total sample at 1 and 3 months after the quit attempt. Chi-square analysis showed significantly higher relapse rates among self-quitters compared to group quitters at both 1 and 3 months. Table 2 , however, only includes raw percentages and takes no other predictors of smoking relapse into account.

The role of post-motivational factors in predicting smoking relapse at I and 3 months after a quit attempt

Table 3 shows the correlations between post-motivational factors (self-efficacy, recovery self-efficacy, and preparatory planning) and relapse at 1 and 3 months after the quit

Table 2. Relapse rates at I- and 3-month follow-ups for the self-quitters and the group quitters

\begin{tabular}{lcc}
$\begin{array}{l}\text { Group } \\
\text { Relapse Rates }(\%)\end{array}$ & $\begin{array}{c}\text { I-month } \\
\text { Relapse rates }\end{array}$ & $\begin{array}{c}\text { 3-month } \\
\text { Relapse rates }\end{array}$ \\
\hline Self-quitters $(N=59)$ & $42(71.2 \%)$ & $54(91.5 \%)$ \\
Group quitters $(N=55)$ & $24(43.6 \%)$ & $37(67.3 \%)$ \\
Total sample $(N=114)$ & $66(57.9 \%)$ & $91(79.8 \%)$ \\
$\chi^{2}$ & $8.86 *$ & $10.40^{*}$ \\
\hline
\end{tabular}

Note. ${ }^{*} p<.05$. 
Table 3. Correlations among relapse at $\mathrm{I}$ and 3 months and the post-motivational variables self-efficacy, recovery self-efficacy, and preparatory planning - stratified by quit modality

\begin{tabular}{|c|c|c|c|c|c|}
\hline & & $\begin{array}{c}\text { Relapse at } \\
\text { I month }\end{array}$ & $\begin{array}{l}\text { Relapse at } \\
3 \text { months }\end{array}$ & $\begin{array}{l}\text { Self- } \\
\text { efficacy }\end{array}$ & $\begin{array}{l}\text { Recovery } \\
\text { self-efficacy }\end{array}$ \\
\hline \multirow[t]{5}{*}{ Self-quitters } & Relapse at I month & & & & \\
\hline & Relapse at third month & $.478^{*}$ & & & \\
\hline & Self-efficacy & $-.325^{*}$ & $-.295^{*}$ & & \\
\hline & Recovery self-efficacy & -.206 & -.051 & .205 & \\
\hline & Preparatory planning & .048 & -.113 & .184 & .008 \\
\hline \multirow[t]{5}{*}{ Group quitters } & Relapse at I month & & & & \\
\hline & Relapse at third month & $.614^{*}$ & & & \\
\hline & Self-efficacy & $-.485^{*}$ & $-.228^{+}$ & & \\
\hline & Recovery self-efficacy & -.190 & -.169 & .201 & \\
\hline & Preparatory planning & $-.298^{*}$ & $-.262^{+}$ & -.008 & $.33 I^{*}$ \\
\hline
\end{tabular}

Note. ${ }^{*} p<.05 ;{ }^{+} p<.10$.

attempt - stratified by quitting modality. In both self-quitters and group quitters, we found moderate positive significant correlations between relapse at the 1 month measurement and relapse at the third month measurement. In self-quitters, we found weak but significant negative correlations between relapse at the 1 as well as the third month measurement and self-efficacy. At the 1 month measurement in group quitters, we found a moderate but significant negative correlation between relapse and self-efficacy and a weak but significant correlation between preparatory planning and relapse. Moreover, we found weak negative correlations of borderline significance between relapse at the third month measurement, and self-efficacy and preparatory planning. Finally, in group quitters, the correlation matrix showed weak but significant positive associations between recovery self-efficacy and planning, suggesting that respondents with higher recovery self-efficacy also make more preparatory plans. The low correlations indicate that preparatory planning, self-efficacy, and recovery self-efficacy measure separate constructs.

In our second hypothesis, we expected low levels of self-efficacy, low levels of recovery self-efficacy, and less preparatory planning to predict smoking relapse. Moreover, as group quitters are motivated to plan and prepare their quit attempt and are provided with strategies to increase (recovery) self-efficacy, in our third hypothesis, we expected low levels of self-efficacy and recovery self-efficacy as well as less preparatory planning to predict relapse in self-quitters but not in group quitters. Table 4 shows the results of logistic regression analysis for relapse 1 month after the quit attempt. The results show a significant effect of self-efficacy (OR $=0.57 ; p<.05)$ and preparatory plans $(\mathrm{OR}=0.40 ; p<.05)$ and a borderline significant effect of age $(\mathrm{OR}=0.93 ; p=.07)$, indicating that having a lower level of self-efficacy, making fewer plans, and younger age increases the risk of relapse at 1 month after the quit attempt. However, the influence of preparatory planning is not interpretable as this factor significantly interacts with the quitting modality (group). The analyses showed a significant effect of interaction between group and preparatory plans $(\mathrm{OR}=4.26 ; p=.045)$, indicating a differential effect of preparatory planning per quitting modality. Simple slope analysis revealed that less preparatory planning predicted relapse among group quitters $(\mathrm{OR}=0.40 ; p=.043)$, 
Table 4. Regression relapse at I month in the variables group - demographical variables, postmotivational variables (self-efficacy, recovery self-efficacy, and preparatory planning), and the interaction terms $(N=113)$

\begin{tabular}{llrrrr}
\hline & \multicolumn{1}{c}{ Variables } & & & \multicolumn{2}{c}{ Cl 95\% } \\
& & \multicolumn{1}{c}{$\mathrm{B}$} & OR & Lower & Upper \\
\hline STEP I & Group (group quitters') & .661 & 1.937 & .733 & 5.119 \\
(ENTER) & Gender (male') & .680 & 1.973 & .734 & 5.305 \\
& Age & $-.076^{+}$ & .927 & .854 & 1.006 \\
& SES (high',2) & .769 & 2.158 & .626 & 7.438 \\
& Self-efficacy (SE) & $-.555^{*}$ & .574 & .439 & .751 \\
& Recovery self-efficacy & -.112 & .894 & .711 & 1.125 \\
& Preparatory plans & $-.926^{*}$ & .396 & .161 & .972 \\
STEP 2 & Group $\times$ Self-efficacy & & & & \\
(BACK-WARD) & Group $\times$ Recovery self-efficacy & & & & \\
& Group $\times$ Preparatory plans & $1.449^{*}$ & 4.257 & 1.030 & 17.586 \\
& $\chi^{2}$ & $44.109^{*}$ & & & \\
& Nagelkerke $R^{2}$ & .435 & & & \\
& Percentage correct prediction & 77.0 & & & \\
\hline
\end{tabular}

Note. ${ }^{*} p<.05,{ }^{+} p<.10$. The model $\chi^{2}$ is significant $(p<.05)$ for all models. 'reference category, ${ }^{2}$ SES was divided into two groups, high and low SES.

but not among the self-quitters $(O R=1.69 ; \mathrm{p}=.333)$. Overall, the model predicted $44 \%$ of the explained variance.

Table 5 shows the results for relapse at 3 months with a significantly higher likelihood of relapse among self-quitters $(\mathrm{OR}=3.56 ; p<.05)$. Next, the results point out that relapse was significantly more likely when respondents had low self-efficacy at the baseline

Table 5. Regression relapse at 3 months on the variables group - demographical variables, post-motivational variables (self-efficacy, recovery self-efficacy, and preparatory planning), and the interaction terms $(N=113)$

\begin{tabular}{|c|c|c|c|c|c|}
\hline & Variables & B & OR & $\begin{array}{l}\mathrm{Cl} 95 \% \\
\text { Lower }\end{array}$ & Upper \\
\hline STEP I & Group (group quitters') & $1.269 *$ & 3.559 & 1.006 & 12.588 \\
\hline \multirow[t]{6}{*}{ (ENTER) } & Gender (male') & .220 & 1.246 & .403 & 3.851 \\
\hline & Age & -.077 & .926 & .844 & 1.016 \\
\hline & SES (high ${ }^{1,2}$ ) & .919 & 2.508 & .688 & 9.139 \\
\hline & Self-efficacy (SE) & $-.337^{*}$ & .714 & .527 & .968 \\
\hline & Recovery self-efficacy & -.092 & .912 & .695 & 1.197 \\
\hline & Preparatory plans & $-.593^{+}$ & .553 & .285 & 1.072 \\
\hline STEP 2 & Group $\times$ Self-efficacy & & & & \\
\hline \multirow[t]{5}{*}{ (BACK-WARD) } & Group $\times$ Recovery self-efficacy & & & & \\
\hline & Group $\times$ Preparatory plans & & & & \\
\hline & $x^{2}$ & $27.104^{*}$ & & & \\
\hline & Nagelkerke $R^{2}$ & .340 & & & \\
\hline & Percentage correct prediction & 80.5 & & & \\
\hline
\end{tabular}

Note. ${ }^{*} p<.05,{ }^{+} p<.10$. The model $\chi^{2}$ is significant $(p<.05)$ for all models. 'reference category, ${ }^{2} \mathrm{SES}$ was divided into two groups, high and low SES. 
measurement $(\mathrm{OR}=0.71 ; p<.05)$. The results for preparatory planning showed a borderline significant effect $(\mathrm{OR}=0.55 ; p=.079)$, indicating that less planning at baseline predicted smoking relapse 3 months after the quit attempt. Finally, none of the interaction terms were of significance in this model, implying that no differences in the effect of preparatory planning, self-efficacy, and recovery self-efficacy for self-quitters and group quitters were found at 3-month follow-up. Overall, this model explained 34\% of the variance.

\section{Additional analyses on the role of recovery self-efficacy}

Two additional analyses were conducted regarding the role of recovery self-efficacy in predicting smoking relapse. First we assessed whether the non-significance of recovery self-efficacy could be due to intercorrelation between self-efficacy and recovery selfefficacy. We checked whether the effects of recovery self-efficacy were suppressed by self-efficacy by running the analyses (complete model as presented in Tables 4 and 5) without (1) the interaction term self-efficacy by group and (2) self-efficacy (main-effect). The first step did not result in a significant effect of recovery self-efficacy, while removal of self-efficacy in the second step revealed that low levels of recovery selfefficacy then significantly predicted relapse at the 1 month post measurement only. The interaction between group and recovery self-efficacy remained non-significant. Second, since moderate levels of recovery self-efficacy lead to more smoking abstinence than low and high levels of recovery self-efficacy (Bandura, 1986; Haaga \& Stewart, 1992), we assessed whether the relationship between relapse and recovery self-efficacy could be a non-linear (curved) relationship. This was done by replacing the initial recovery self-efficacy term by a squared term of the same construct. The results pointed out a differential effect of recovery self-efficacy per group $(p=.064)$ at the first month measurement. Simple slope analyses aimed at assessing the role of recovery self-efficacy per group revealed a borderline significant effect $(\mathrm{OR}=1.192 ; p=.095)$ - indicating an association between low and high levels of recovery self-efficacy and relapse among group quitters and a non-significant effect $(\mathrm{OR}=.914 ; p=.371)$ in self-quitters. The effect of recovery self-efficacy at the third month measurement was non-significant $(\mathrm{OR}=1.030 ; p=.704)$.

\section{Discussion}

The main goal of this study was to identify the role of (low) baseline levels of (recovery) self-efficacy and (less) preparatory planning with regard to smoking relapse among smokers who are motivated to quit smoking. Our findings regarding self-efficacy showed that low levels of self-efficacy predict relapse and confirm the results of previous studies (Amodei \& Lamb, 2005; Dijkstra \& Borland, 2003; Dijkstra \& de Vries, 2000;Gwaltney, et al., 2009; Gwaltney, Shiffman, Balabanis, \& Paty, 2005; Mudde, et al., 1995; Ockene et al., 2000). Regarding recovery self-efficacy, however, our study did not reveal a significant effect on relapse at 1 and 3 months. This might have been due to the intercorrelation between self-efficacy and recovery self-efficacy. We tested this assumption and the results indicated that removing self-efficacy revealed that low levels of recovery self-efficacy then significantly predicted relapse at the 1 month post measurement, but not at the 3 months post measurement. The interaction term between recovery self-efficacy and group remained non-significant. Yet, these effects of recovery self-efficacy are likely to 
be attributed to the general efficacy-related aspect of recovery self-efficacy instead of specific relapse-related aspects of the construct. Moreover, this finding suggests that the effects of general self-efficacy were greater than the effects of recovery self-efficacy. Finally, since moderate levels of recovery self-efficacy lead to more smoking abstinence than low and high levels of recovery self-efficacy (Bandura, 1986; Haaga \& Stewart, 1992), we conducted additional analyses to test whether a non-linear association existed between recovery self-efficacy and relapse. Our additional analyses, however, indicated non-significant effects of recovery self-efficacy for both the first and the third month. Yet, the first month results were of borderline significance in group quitters, a finding that supports the role of both low as well as high levels of recovery self-efficacy on relapse. Our borderline significant effect may be the result of a relatively small sample size. Therefore, more research regarding the role of recovery self-efficacy in smoking relapse is needed.

Regarding planning, our findings are in line with those of an earlier Dutch study revealing that less preparatory planning predicts smoking relapse (Hoving, et al. 2006). Our study indicates that less planning predicted relapse at 1 month after the quit attempt. However, only a borderline significant effect of planning was found 3 months after the quit attempt. The latter might be due to the possibly limited power of the study since the sample size was small. Moreover, the results for the main effect of preparatory planning at the 1 month measurement are not interpretable, as we found a significant interaction effect of planning by group, indicating differential effects of preparatory planning per group at the 1-month follow-up. Contrary to our expectations, the simple slope analysis revealed that low levels of planning were predictive of relapse in group quitters, but not in self-quitters. As far as we know, there are no previous studies on this issue. A possible explanation for this effect may be that planning needs to be combined with actual practice. This would imply that group quitters who made preparatory plans (high levels of planning) actually carried out these plans more frequently as they may have received more encouragement and support to prepare and carry out plans to quit. However, we had no data to test this assumption. We hypothesized that the amount of planning at baseline would not be predictive for group quitters as we expected them to learn and to be stimulated to form and carry out plans (as a result of group processes and the intervention aims), this contradictory finding prompts further research into the effects of the intervention and group processes on immediate outcomes such as planning.

With regard to the influence of demographic variables and quitting modality (selfquitters or group quitters) on relapse, our results indicate that those who quitted without the help of a smoking cessation course had the highest risk of relapse at 3 months. These findings are line with studies regarding the efficacy of group help in the process of smoking relapse (Lancaster \& Stead, 2005; Willemsen et al., 2003). However, as our study was non-randomized, it remains difficult to interpret the findings regarding quitting modality. No significant effects were found regarding age, gender, and SES. Overall, the model explained $44 \%$ and $34 \%$ of the variance, 1 and 3 months after the quit attempt, respectively, suggesting that this model was better at predicting immediate relapse than later relapse.

Next, we assessed differences between self-quitters and group quitters at the prequit measurement. Our results showed higher levels of baseline self-efficacy among group respondents. The literature however, suggests that respondents who decide to participate in a smoking cessation intervention have lower levels of self-efficacy (and therefore seek help with their quit attempt) (Hublet et al., 2002; Pohl et al., 1998). 
A possible explanation for our contradictory finding might be that group quitters are often referred to the courses by their general practitioner or their employer, which may overrule the role of self-efficacy. Furthermore, it is worth mentioning that the average levels of self-efficacy in the group quitters were (although somewhat higher than those of self-quitters) still not very high (mean around four implying neutral regarding selfefficacy). Finally, although caution is needed because of our quasi-experimental study design, our findings support the conclusions of the Cochrane Review which found individual counselling to be more effective than no counselling (Lancaster \& Stead, 2005) by showing significantly large differences in relapse rates between self-quitters and group quitters at 1 and 3 months after the quit attempt.

The last goal of the study was to gain in-depth information on the differences between self-quitters and group quitters by assessing whether the role of self-efficacy, recovery self-efficacy, and preparatory planning differed between the groups. Besides the previous mentioned differential effect of preparatory planning, no differential effects were found for self-efficacy and recovery self-efficacy at both the 1- and 3-month follow-up.

This study is subject to limitations. First, measurements of smoking abstinence were based on self-reports, which were not verified with biochemical validation. However, previous studies have suggested that the difference between self-reported results and verified results is negligible (Patrick et al., 1994; Velicer, Prochaska, Rossi, \& Snow, 1992). Second, the respondents' answers regarding the quit attempt were also based on self-reports. However, this is an inevitable limitation of self-report studies. Third, we used a dichotomous outcome variable. Studies have shown that dichotomizing a continuous primary outcome may result in loss of information (Bakhshi, Eshraghian, Mohamed, \& Seifi, 2008; Moser \& Coombs, 2004). In smoking-related studies, the use of a dichotomous-dependent outcome measure (relapse vs. abstinence) is standard (Hall, et al., 2001; Hughes, Keely, \& Niaura, 2003; West et al., 2005). Fourth, the study design was quasi-experimental. This, however, is of less importance in our study since the main goal was to identify the determinants of smoking relapse and not to show the effectiveness of an intervention per se. Fifth, we measured preparatory planning only, while it would have been useful to have information about the realization of intended plans. Therefore, we suggest conducting this information in future studies. Sixth, we did not assess changes in cognitions (self-efficacy and planning) due to group participation. Measuring this, however, would have been useful as it would have helped us to gain insight into possible mediation processes. Seventh, we only assessed income as an indicator for SES, whereas additional information about education and occupation may have given a more complete picture of the SES status of our respondents. Finally, our study measured only short-term relapse at 3 months, while research shows that short-term (within 6 months) abstinence does not always accurately predict long-term abstinence (more than 1 year) (Fiore et al., 2008). However, as preliminary research our short-term findings are still valuable for future studies and interventions.

To our knowledge, this is the first study to show a differential effect of preparatory planning and indicates that planning is a significant predictor of relapse for group quitters, but not for self-quitters. An explanation might be that group quitters (who engage in more planning) are motivated by the course trainers to carry out their plans. Participating in a smoking cessation course can therefore encourage quitters to carry out their plans. It should also encourage the development of planning. As these are only preliminary results and the latter issue remains unclear, more research is needed into the efficacy of making and carrying out preparatory plans for group quitters as well as for selfquitters. In addition, we suggest for the future, researching how to motivate smokers 
to carry out their plans, without participating to cessation courses. Future research could also investigate how group interventions could influence respondents who are not preparing their quit attempt by making preparatory plans, such as moving smokers' requisites. In line with other studies, we found that low levels of self-efficacy at the pre-quit measurement are of great importance in the smoking relapse process. Finally, the results showed that self-quitters, quitting without help, are at higher risk of smoking relapse at 3 months compared to group quitters. In general, our study shows that low selfefficacy and, to a lesser extent, a low level of planning is consistent predictors of relapse. The role of recovery self-efficacy remains unclear and needs further research. Finally, we recommend dismantling experimental studies with regard to the effects of self-efficacy, preparatory planning, and recovery self-efficacy in relapse prevention programmes.

\section{Acknowledgements}

This study was funded by ZonMw, the Netherlands Organization for Health Research and Development. We would like to thank the trainers of the smoking cessation courses held by STIVORO, the Dutch Foundation for a Smoke-Free Future, for helping to recruit participants. Finally, we would like to thank all the people who participated in the study.

\section{References}

Abraham, C., Sheeran, P., Norman, P., Conner, M., de Vries, N., \& Otten, W. (1999). When good intentions are not enough: Modeling post decisional cognitive correlates of condom use. Journal of Applied Social Psychology, 19, 2591-2612. doi:10.1111/j.1559-1816.1999. tb00127.x

Aiken, L., \& West, S. (1991). Multiple regression: Testing and interpreting interactions (New ed.). Newbury Park: Sage Publications.

Ajzen, I. (1988). Attitudes, personality and behavior. Milton Keynes: Open University Press.

Ajzen, I. (1991). The theory of planned behavior. Organizational Behavior and Human Decision Processes, 50, 179-211. doi:10.1016/0749-5978(91)90020-T

Ajzen, I., \& Fishbein, M. (1980). Understanding attitudes and predicting social behavior. Englewood-Cliff, New York: Prentice-Hall.

Allen, S. S., Bade, T., Hatsukami, D., \& Center, B. (2008). Craving, withdrawal, and smoking urges on days immediately prior to smoking relapse. Nicotine and Tobacco Research, 10(1), 35-45. doi:10.1080/14622200701705076

American Cancer Society (2010). The great American bealth challenge: Helping a smoker quit: Dos and don'ts. Retrieved from http://www.cancer.org/docroot/subsite/greatamericans/ content/Helping_a_Smoker_Quit.asp

Amodei, N., \& Lamb, R. J. (2005). Predictors of initial abstinence in smokers enrolled in a smoking cessation program. Substance Use and Misuse, 40, 141-149. doi:10.1081/JA-200047556

Bakhshi, E., Eshraghian, M., Mohamed, K., \& Seifi, B. (2008). A comparison of two methods for estimating odds ratios: Results from the National Health Survey. BioMed Central Medical Research Methodology, 8(78), 1188-1178. doi:10.1186/1471-2288-8-78

Bandura, A. (1986). Social foundations of thought and action: A social cognitive theory. New York: Prentice-Hall.

Bandura, A. (1997). Self-efficacy: The exercise of control. New York: Freeman.

CBO. (2009). Richtlijn behandeling van Tabaksverslaving herziening 2009 [Guideline for the treatment of tobacco addiction - revision 2009]. Alphen aan den Rijn: Author.

CDC. (2002). Cigarette smoking among adults - United States, 2000. 51(29): Author. 
Cokkinides, V., Ward, E., Jemal, A., \& Thun, M. (2005). Under-use of smoking-cessation treatments: Results from the National Health Interview Survey, 2000. American Journal of Preventive Medicine, 28(1), 19-22. doi:10.1016/j.ampre.2004.09.007

Danaei, G., Rimm, E. B., Oza, S., Kulkarni, S. C., Murray, C. J. L., \& Ezzati, M. (2010). The promise of prevention: The effects of four preventable risk factors on national life expectancy and life expectancy disparities by race and county in the United States. PLOS Medicine, 7(3), e1000248. doi:10.1371/journal.pmed.1000248

De Vries, H., Kremers, S. P. J., Smeets, T., Brug, J., \& Eijmael, K. (2008). The effectiveness of tailored feedback and action plans in an intervention addressing multiple health behaviors. American Journal of Health Promotion, 22(6), 417-425.

De Vries, H., Mudde, A., Leijs, I., Charlton, A., Vartiainen, E., Buijs, G., ... Kremers, S. (2003). The European Smoking Prevention Framework Approach (EFSA): An example of integral prevention. Health Education Research, 18(5), 611-626. doi:10.1093/her/cyg033

Dijkstra, A., \& Borland, R. (2003). Residual outcome expectations and relapse in ex-smokers. Health Psychology, 22(4), 340-346. doi:10.1037/0278-6133.22.4.340

Dijkstra, A., \& De Vries, H. (2000). Self-efficacy expectation with regard to different tasks in smoking cessation. Psychology and Health, 15(4), 501-511. doi:10.1080/08870440008402009

Dijkstra, A., de Vries, H., \& Bakker, M. (1996). Pros and cons of quitting, self-efficacy, and the stages of change in smoking cessation. Journal of Consulting and Clinical Psychology, 64, 758-763. doi:10.1037/0022-006X.64.4.758

Fiore, M., Jean, C. R., Baker, T. B., Bailey, W. C., Benowitz, N. L., Curry, S. J., .. Wewers, L. (2008). Treating tobacco use and dependence: Update 2008. Rockville, MD: U.S. Department of Health and Human Services, Public Health Service, Public Health Service.

Fishbein, M., \& Ajzen, I. (2010). Predicting and changing behavior: The reasoned action approach. New York: Psychology Press (Taylor and Francis).

Gollwitzer, P. M., \& Moskowitz, G. B. (1996). Goal effects on action and cognition, Handbook of basic principles. New York: Guilford.

Gwaltney, C. J., Metrik, J., Kahler, C. W., \& Shiffman, S. (2009). Self-efficacy and smoking cessation: A meta-analysis. Psychology of Addictive Behaviors, 23(1), 56-66. doi:10.1037/a0013529

Gwaltney, C. J., Shiffman, S., Balabanis, M. H., \& Paty, J. A. (2005). Dynamic self-efficacy and outcome expectancies: Prediction of smoking lapse and relapse. Journal of Abnormal Psychology, 114(4), 661-675. doi:10.1037/0021- 843X.114.4.661

Haaga, D., \& Stewart, B. (1992). Self-efficacy for recovery from lapse after smoking cessation. Journal of Consulting and Clinical Psychology, 6O(1), 24-28. doi:10.1037/0022-006X.60.1.24

Hajek, P., Stead, L. F., West, R., \& Jarvis, M. (2005). Relapse prevention interventions for smoking cessation. Cochrane Database of Systematic Reviews, (1.) Art. No.: CD003999. doi:10.1002/14651858.CD003999.pub3

Hall, S., Delucchi, K. L., Velicer, W. F., Kahler, C. W., Ranger-Moore, J., Hedeker, D., . . , Niaura, R. (2001). Statistical analysis of randomized trials in tobacco treatment: Longitudinal designs with dichotomous outcome. Nicotine and Tobacco Research, 3(3), 193-202. doi:10.1080/ 14622200110050411

Health Canada. Canadian Tobacco Use Monitoring Survey 2001: An overview. Retrieved from: http://www.hc-sc.gc.ca/hc-ps/tobac-tabac/research-recherche/stat/_ctums-esutc_2001/ ar-rpa-2001-eng.php

Hilberink, S., Jacobs, J., Schlosser, M., Grol, R., \& De Vries, H. (2006). Characteristics of patients with COPD in three motivational stages related to smoking cessation. Patient Education and Counselling, 61, 449-457. doi:10.1016/j.pec.2005.05.012

Hoving, E., Mudde, A., \& De Vries, H. (2006). Predictors of smoking relapse in a sample of Dutch adult smokers: The roles of gender and action plans. Addictive Behaviors, 31, 1177-1189. doi:10.1016/j.addbeh.2005.09.002

Hublet, A., Maes, L., \& Csincsak, M. (2002). Predictors of participation in two different smoking cessation interventions at school. Health Education and Behavior, 29(5), 585-595. doi:10. $1177 / 109019802237026$ 
Hughes, J. R., Keely, J., \& Naud, S. (2004). Shape of the relapse curve and long-term abstinence among untreated smokers. Addiction, 99(1), 29-38. doi:10.1111/j.1360-0443.2004.00540.x

Hughes, J. R, Keely, J., \& Niaura, R. (2003). Measures of abstinence in clinical trials: Issues and recommendations. Nicotine and Tobacco Research, 5, 13-25. doi:10.1093/ntr/5.1.13

Jones, F., Abraham, C., Harris, P., Schulz, J., \& Chrispin, C. (2001). From knowledge to action regulation: Modeling the cognitive prerequisites of sun screen use in Australian and UK samples. Psychology and Health, 16, 191-206.

Lancaster, T., \& Stead, L. F. (2005). Individual behavioral counselling for smoking cessation. Cochrane Database of Systematic Reviews (2), CD001292. doi:10.1002/14651858

Luszczynska, A., \& Schwarzer, R. (2003). Planning and self-efficacy in the adoption and maintenance of breast self-examination: A longitudinal study on self-regulatory cognitions. Psychology and Health, 18, 93-108. doi:10.1080/0887044021000019358

Marlatt, G. A., Baer, J. S., \& Quigley, L. A. (1995). Self-efficacy and addictive behavior. In A. Bandura (Ed.), Self-efficacy in changing societies (pp. 289-315). New York: Cambridge University Press.

Marlatt, G. A., \& Donovan, D. M. (2005). Relapse prevention, maintenance strategies in the treatment of addictive behaviors (2nd ed.). New York: Guilford Publications, Inc.

Marlatt, G. A., \& Gordon, J. R. (1985). Relapse prevention: Maintenance strategies in the treatment of addictive behaviors. New York: Guilford Press.

Moser, B., \& Coombs, L. (2004). Odds ratios for a continuous outcome variable without dichotomizing. Statistics in Medicine, 23, 1843-1860. doi:10.1002/sim.1776

Mudde, A., Kok, G., \& Strecher, V. (1995). Self-efficacy as a predictor for the cessation of smoking: Methodological issues and implications for smoking cessation programs. Psychology and Health, 10, 353-367. doi:10.1080/08870449508401956

Nagelhout, G., de Korte, D., Zeegers, T., Van Der Meer, R., \& Willemsen, M. (2010). Themapublicatie Hulpmiddelen voor stoppen met roken 2001-2009 [Theme publication aids for smoking cessation 2001-2009]. Den Haag: Stivoro.

Ockene, J., Emmons, K., Mermelstein, R., Perkins, K., Bonollo, D., \& Voorhees, C. (2000). Relapse and maintenance issues for smoking cessation. Health Psychology, 19(1 suppl), 17-31. doi:10. 1037/0278-6133.19.Supp11.17

Patrick, D. L., Cheadle, A., Thompson, D. C., Diehr, P., Koepsell, T., \& Kinne, S. (1994). The validity of self-reported smoking: A review and meta-analysis. American Journal of Public Health, 84(7), 1086-1093.

Pohl, J. M., Martinelli, A., \& Antonakos, C. (1998). Predictors of participation in a smoking cessation intervention group among low-income women. Addictive Behaviors, 23(5), 699-704. doi:10. 1016/S0306-4603(98)00017-3

Rise, J., Thompson, M., \& Verplanken, B. (2003). Measuring implementation intentions in the context of the theory of planned behavior. Scandinavian Journal of Psychology, 44, 87-95. doi:10.1111/1467-9450.00325

Rogers, R. W. (1983). Cognitive and physiological processes in fear appeals and attitude change: A revised theory of protection motivation. In J. T. Cacioppo \& R. E. Petty (Eds.), Social psychophysiology: A source book. New York: Guilford Press.

Sheeran, P. (2002). Intention-behavior relations: A conceptual and empirical review. In W. Strobe \& M. Hewstone (Eds.), European review of social psychology (Vol. 12, pp. 1-30). Chichester, UK: Wiley.

Sun, X., Prochaska, J. O., Velicer, W. F., \& Laforge, R. G. (2007). Transtheoretical principles and processes for quitting smoking: A 24-month comparison of a representative sample of quitters, relapsers, and non-quitters. Addictive Behaviors, 32(12), 2707-2726. doi:10.1016/j.addbeh. 2007.04.005

STIVORO (2010). Van onderop en van bovenaf: De toekomst van tabaksontmoediging in Nederland 2011-2020 [The future of tobacco control]. Den Haag: Author. 
Te Poel, F., Bolman, C., Reubsaet, A., \& De Vries, H. (2009). Efficacy of a single computer-tailored email for smoking cessation: Results after six months. Health Education Research, 24(6), 930-940. doi:10.1093/her/cyp036

Velicer, W., Prochaska, J., Rossi, J., \& Snow, M. (1992). Assessing outcome in smoking cessation studies. Psychological Bulletin, 11, 23-41. doi:10.1037/0033-2909.111.1.23

Webb, T. L., \& Sheeran, P. (2006). Does changing behavioral intentions engender behavior change? A meta-analysis of the experimental evidence. Psychological Bulletin, 132(2), 249-268. doi:10.1037/0033-2909.132.2.249

West, R., Hajek, P., Stead, L., \& Stapleton, J. (2005). Outcome criteria in smoking cessation trials: Proposal for a common standard. Addiction, 100, 299-303. doi:10.1111/j.1360-0443.2004. 00995.x

WHO (2001). WHO evidence based on recommendations on the treatment of tobacco dependence. Copenhagen: Author.

Willemsen, M., Wagema, E. J., \& Schayck van, C. P. (2003). De effectiviteit van stoppen-met-roken methoden die in Nederland beschikbaar zijn: een systematische review op basis van Cochrane gegevens. Nederlands Tijdschrift voor Geneeskunde [Dutch Journal of Medicine], 147(19), 922-927.

Zhu, S., Melcer, T., Sun, J., Rosbrook, B., \& Pierce, J. (2000). Smoking cessation with and without assistance: A population based analysis. American Journal of Preventive Medicine, 18, 305311.

Zhu, S. H., Stretch, V., Balabanis, M., Rosbrook, B., Sadler, G., \& Pierce, J. P. (1996). Telephone counselling for smoking cessation: Effects of single-session and multiple-session interventions. Journal of Consulting and Clinical Psychology, 64, 202-211.

Zimmermann, B. (2000). Attaining self-regulation: A social cognitive perspective. Handbook of self-regulation (pp. 13-39). San Diego: Academic Press.

Received I8 August 2010; revised version received I3 April 20 I I 